\title{
Minimizing pain during childhood vaccination injections: improving adherence to vaccination schedules
}

This article was published in the following Dove Press journal:

Pediatric Health, Medicine and Therapeutics

30 September 2014

Number of times this article has been viewed

\author{
Lacey M Eden \\ Janelle LB Macintosh \\ Karlen E Luthy \\ Renea L Beckstrand \\ College of Nursing, Brigham Young \\ University, Provo, UT, USA
}

Correspondence: Karlen E Luthy

College of Nursing, Brigham Young

University, 457 SWKT, Provo,

UT 84602, USA

$\mathrm{Tel}+\mathrm{I} 80 \mathrm{I} 4226683$

Fax +I 80I 4220536

Email beth_luthy@byu.edu

\begin{abstract}
Pain experienced in childhood can lead to long-term and psychologically detrimental effects. Unfortunately, the most common pain experienced in childhood is caused by vaccinations and may lead to non-adherence to the recommended vaccination schedule. As a result, it is the health care provider's responsibility to take measures to reduce vaccination pain; however, there are a plethora of pain relieving interventions during immunizations and it is unclear which interventions are most cost efficient, timely, and effective. Studies have been conducted to investigate the efficacy of different pain management interventions during vaccinations. This review evaluates various pain relieving interventions and provide health care providers age appropriate guidance on pain relieving interventions during vaccinations. Employment of these strategies may successfully reduce vaccination-associated pain in infants, children, and adolescents, and may improve compliance with the vaccination schedule.
\end{abstract}

Keywords: immunization, intervention, effective, compliance

\section{Introduction}

Vaccinations are the safest and most effective way to prevent serious illness and death. ${ }^{1}$ In fact, vaccinations prevent approximately 2.5 million deaths every year. ${ }^{2}$ However, despite the success of vaccinations in preventing morbidity and mortality, some countries struggle to maintain high levels of vaccination uptake. ${ }^{3}$ For example, in 2011 only 69\% of American children aged 19-35 months had fully completed a combined series of childhood vaccinations. ${ }^{4}$

The Centers for Disease Control and Prevention recommends vaccinations to prevent 17 life-threatening diseases; ${ }^{5}$ consequently, adherence to the recommended vaccination schedule means children will receive an average of 18-24 injections by the time they are 2 years old. ${ }^{1}$ Notwithstanding the protection vaccinations provide against so many diseases, some parents delay or refuse childhood vaccinations for a variety of reasons. ${ }^{1} \mathrm{~A}$ few of the common parental reasons for refusing childhood vaccinations include questioning vaccination safety, distrust of the government, concern about contraindications with a child's underlying medical condition, as well as the pain and anxiety associated with needle puncture. ${ }^{1,6}$

Unfortunately, vaccinations are the most common painful and anxiety producing procedures to take place in the outpatient health care clinic, although health care providers (HCPs) usually consider vaccinations to be a benign procedure ${ }^{7}$ requiring little intervention. ${ }^{8}$ Nevertheless, some children experience intense anxiety regarding vaccinations, a reaction that may result in non-adherence to the recommended vaccination schedule. ${ }^{9,10}$ Vaccination-related pain and anxiety is most often associated with a fear of 
needles, which continues into adulthood for about $25 \%$ of the population. ${ }^{11}$ Unfortunately, two out of every three adults with needle phobia are less likely to vaccinate their own children. ${ }^{11}$ Despite the fact that needle-associated pain during vaccinations is a surmountable barrier, it is still a main reason for noncompliance to the vaccination schedule. ${ }^{6,12}$ Thus, HCPs should be aware of these issues and employ techniques to reduce anxiety and pain during vaccinations, ${ }^{13}$ an act that may promote adherence to the vaccination schedule.

Pain assessment in children is unique due to factors such as the child's age, developmental level, cognitive and communication skills, and past experiences with pain. Similarly, these variables make effective pain management difficult, requiring consideration of the child's developmental stage. Pain management during vaccination should be individualized to incorporate strategies most effective for the patient's age. ${ }^{14}$ Studies have been conducted to investigate the efficacy of different pain management strategies during vaccinations. There are numerous strategies for relieving vaccination pain, making it difficult for HCPs to decide which pain relieving strategy is the most effective. Consequently, the purpose of this literature review is to evaluate various pain management strategies regarding vaccinations and to make a recommendation on which intervention is the most appropriate according to the patient's age.

\section{Methods}

An electronic search using CINAHL, MEDLINE, and the Cochrane Library was conducted to identify studies published between 1995 and 2014. The search terms included immune pain, vaccine pain, pain relief, pain strategies, and pain techniques. Additionally, the references found in Taddio et $\mathrm{al}^{6}$ were investigated for further research not found on the initial electronic search. Inclusion criteria consisted of studies investigating non-pharmacological pain-relieving strategies for vaccination-related pain in children aged 0-18 years. Articles not published in English were excluded, as well as studies investigating prescription pain relievers and injection techniques for pain relief, as well as articles including adult subjects. Of the 118 articles found, 29 met the inclusion criteria for this literature review.

\section{Results}

There were 29 studies that met the inclusion criteria. Vaccination pain relieving strategies can be grouped into four main categories: 1) topical anesthetics, 2) distraction, 3) positioning, and 4) $\mathrm{pH}$ of vaccination. Five studies investigated the effectiveness of topical anesthetics. Distraction techniques, namely video, music, tactile, blowing, and oral distraction (ie, breastfeeding or sucrose) were explored in 16 studies. Three studies examined the relationship between patient positioning and vaccination pain. Finally, four studies assessed a relationship between the $\mathrm{pH}$ of vaccinations and vaccination-related pain. The 29 studies were conducted in Canada, Sweden, France, United States, Iran, Jordan, and Turkey.

\section{Topical anesthetics}

Five randomized controlled studies examined the use of topical anesthetics to reduce pain during vaccinations (see Table 1). ${ }^{15-19}$ Vapocoolant and lidocaine-prilocaine cream ( $5 \%$ eutectic emulsion of lidocaine $[25 \mathrm{mg} / \mathrm{g}]$ and prilocaine [25 mg/g]) are both topical anesthetics approved for pain reduction during pediatric procedures, such as vaccinations. The studies investigated the effectiveness of these topical anesthetics.

Two studies evaluated the lidocaine-prilocaine patch compared with a placebo patch. ${ }^{16,18}$ Cassidy et al ${ }^{16}$ used several pain measurement tools in this study, including 1) the visual analog scale (VAS) for pain and anxiety rated by parents and technicians, 2) the Faces Pain Scale (FPS) where children rated their own pain, and 3) the Children's Hospital of Eastern Ontario Pain Scale (CHEOPS) and the Child Facial Coding System used by the research assistants. A significant reduction of pain $(P<0.001)$ was reported with use of the lidocaine-prilocaine patch when compared with the placebo patch in children 4-6 years of age.

In a similar study, using the modified behavioral pain scale (MBPS) scored by blinded research assistants, lidocaine-prilocaine cream was found to be more effective compared with placebo $(P<0.042)$ in reducing vaccination pain in infants 12 months old. ${ }^{18}$ In each of these studies, $1 \mathrm{~g}$ of lidocaine-prilocaine cream was applied to a patch in the treatment group, and $1 \mathrm{~g}$ of an inert oil was used in the placebo group. The intervention was applied 60-120 minutes prior to the vaccination and was not removed more than 10 minutes before the vaccination took place. Although lidocaine-prilocaine cream is proven to be effective in the reduction of vaccination pain, ${ }^{16,18,20,21}$ it is not feasible to apply a patch 60-120 minutes prior to injection.

In contrast, vapocoolant spray is an inexpensive topical anesthetic with an application recommendation of 1-2 minutes prior to procedure. ${ }^{15}$ Two studies compared the effectiveness of vapocoolant spray with a placebo in reducing vaccination pain. ${ }^{15,17}$

Cohen et al ${ }^{17}$ used several pain measurement tools including the Child-Adult Medical Procedure Interaction Scale 


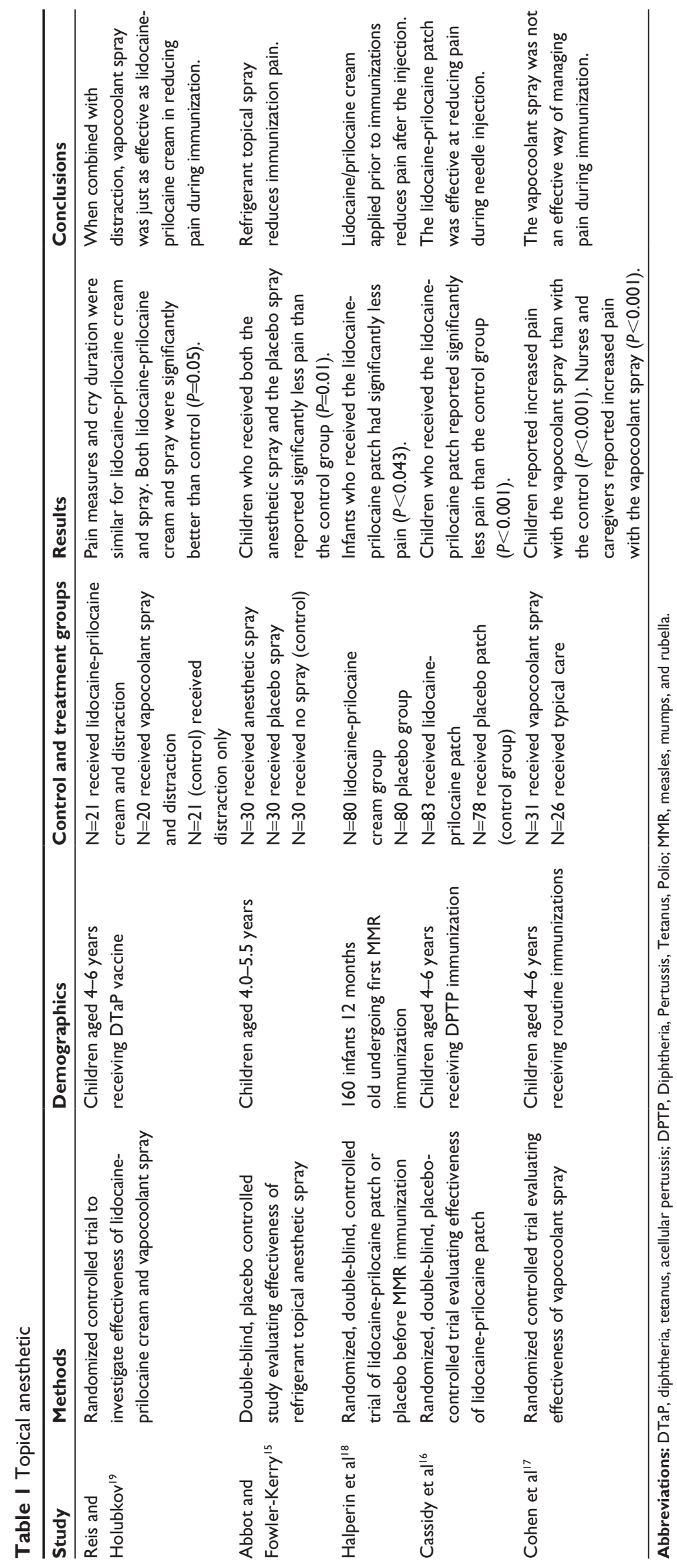


(CAMPIS), the FPS-Revised (FPS-R), and VAS scoring by the caregiver and nurse. Interestingly, FPS-R results found vapocoolant spray actually heightened the pain response $(P<0.001)$ during vaccination. ${ }^{17}$ The analysis of the CAMPIS and VAS scoring did not find significant support for vapocoolant in reducing vaccination pain. However, the sample size $(n=57)$ was insufficient to accurately identify any differences between the treatment and placebo groups. Conversely, Abbott and FowlerKerry ${ }^{15}$ found a significant reduction in pain with the use of vapocoolant spray $(P<0.01)$ using the VAS scale rated by the child and the parent. However, a significant reduction in pain was also reported with the placebo intervention when compared with the control group who had no treatment $(P=0.01)$.

Reis and Holubkov ${ }^{19}$ investigated topical anesthetics combined with distraction, a non-pharmacological treatment, as an intervention to relieve vaccination pain. Several pain and distress scales were completed by the child, parent, nurse, and blinded observer. Scores on VAS questionnaires were assessed for prior pain experience, vaccination pain, and parental distress. Additionally, the Global Mood Scale, Observational Scale of Behavior Distress (OSBD), and cry duration were used to measure findings. In the lidocaineprilocaine cream plus distraction and the vapocoolant plus distraction groups, there was a significant decrease in vaccination pain scores; however, there was no significant difference in pain reduction between the lidocaine-prilocaine cream and vapocoolant groups. When compared with the distraction only group, lidocaine-prilocaine cream plus distraction and vapocoolant plus distraction were superior in relieving vaccination pain $(P<0.05) .{ }^{19}$

\section{Distraction}

\section{Video distraction}

Video distraction, as with all non-pharmacologic pediatric pain management, has few to no side-effects, is easily accessible, and is inexpensive. ${ }^{22}$ In three studies, video was used as the means for distraction during vaccinations. ${ }^{23-25}$ In all three studies, the findings were insignificant (Luthy et al, ${ }^{23}$ $P<0.801$; Cohen et al, ${ }^{24} t(123)=1.49$; and Cohen, ${ }^{25} P<0.17$ ). The children in the Luthy et $\mathrm{al}^{23}$ study ranged in age from 2 to 12 years. An evaluation tool assessed the parent's perception of the child's pain using the Wong-Baker FACES Pain Rating Scale, a Likert scale rating anxiety, and a comparison of the current vaccination experiences with the most recent vaccination experience. The tools used to measure outcomes were limited to parent response; results may have differed had the child discussed their experience with video distraction during the vaccination procedure.
Cohen et $\mathrm{al}^{24}$ and Cohen ${ }^{25}$ evaluated video distraction in children 1 month to 3 years of age. Infant pain measurements require rating behaviors such as crying, facial expressions, flailing of arms and legs, and state of arousal, as well as evaluating physiological factors such as heart rate, breathing patterns and blood pressure. ${ }^{24}$ Cohen et $\mathrm{al}^{24}$ used the Measure of Adult and Infant Soothing and Distress (MAISD) rating scale that evaluates the behaviors of infants, parents, and nurses during painful medical procedures in infants. Additionally, research assistants completed VAS scoring as another evaluation tool. In a similar study, Cohen ${ }^{25}$ used several evaluation tools including MBPS, the Children's Hospital of Eastern Ontario Pain Scale, parent and nurse VAS scoring; and heart rate before, during, and after the vaccination. The studies involving infants found stress was significantly reduced prior to injection $(P<0.001)$ and after injection $(P<0.05)$, but there was no improvement in pain during the vaccination. ${ }^{24,25}$

\section{Music distraction}

Two studies focused on music therapy and vaccination pain (see Table 2). ${ }^{7,26}$ With so few studies examining music therapy specific to vaccination pain, it is beneficial that these two studies incorporate participants in a variety of age groups. One study was completed on children 3-6 years of age, ${ }^{7}$ and the other study was completed on adolescents 13-25 years old. ${ }^{26}$

Megel et $\mathrm{al}^{7}$ included the OSBD scale and the Oucher Pain Scale and measured heart rate and blood pressure in children 3-6 years old during vaccinations. The results found physiological indicators of stress or pain were not significantly reduced with music distraction during vaccinations. Interestingly, according to the adapted questionnaire from the World Health Organization-Euro cross-nation study for health-related behaviors in school children, adolescents were found to have a statistically lower pain experience $(P<0.013)$ when using music distraction without headphones. ${ }^{26}$ Music is a crucial part of adolescent culture, which may account for why music distraction is more effective in relieving vaccinerelated pain in the adolescent age group.

\section{Tactile distraction}

Tactile distraction during vaccination is based upon the Gate Control Theory of Pain. ${ }^{27}$ The theory is grounded in the idea that there is a gate in the spinal cord's dorsal horn that can facilitate or inhibit pain transmission to the brain. When the skin is touched, neuro-fibers are stimulated and "close the gate," preventing pain signals from reaching the 


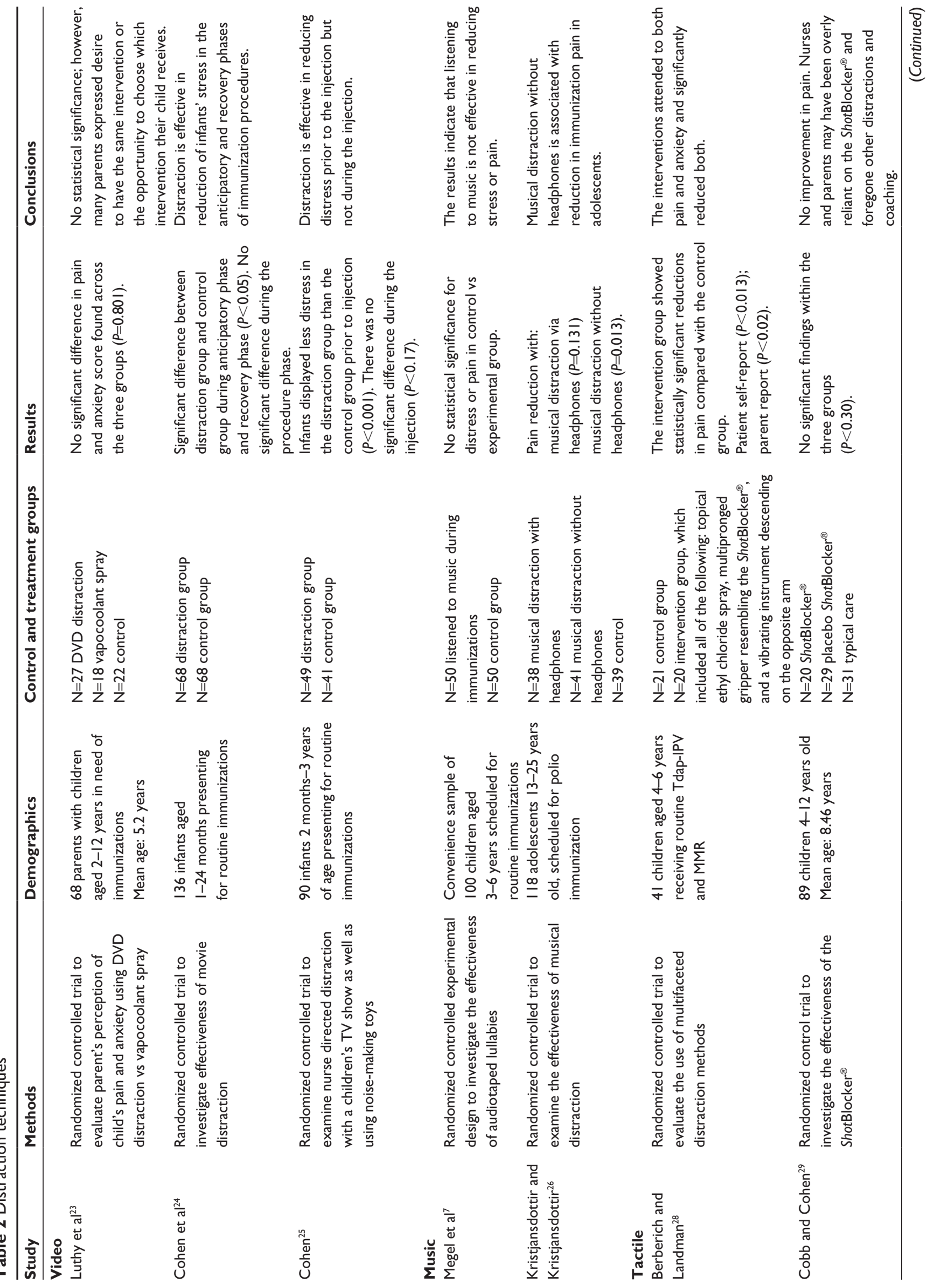




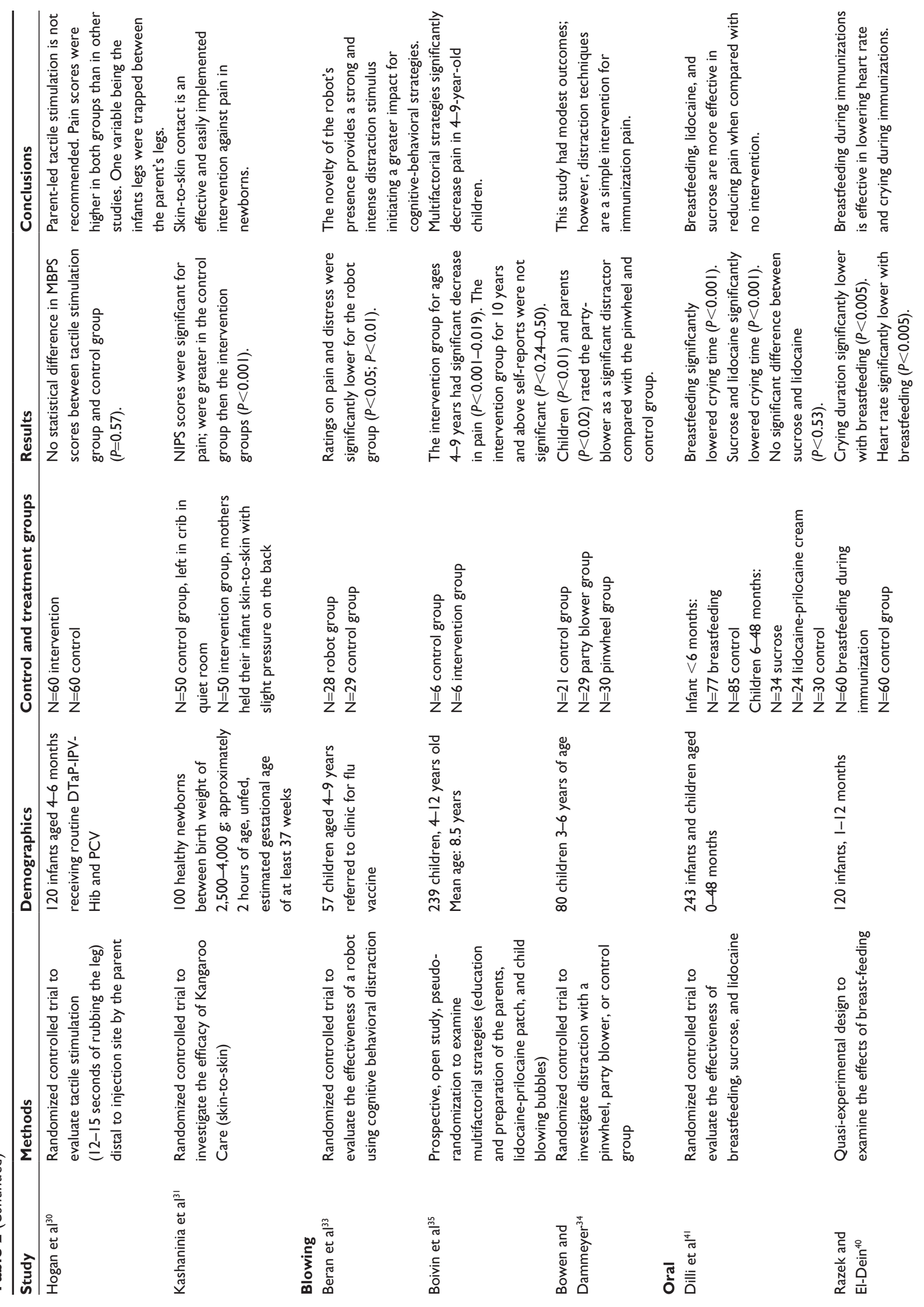




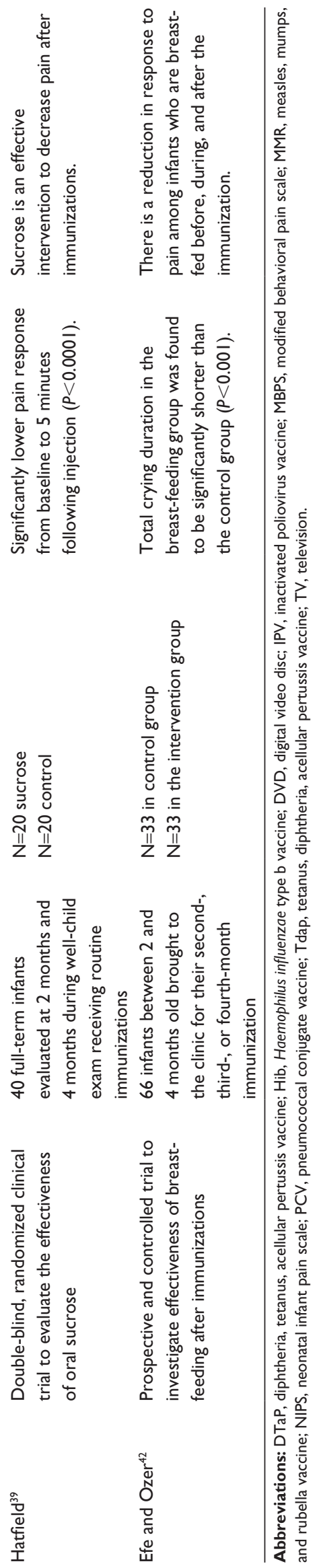

brain. ShotBlocker ${ }^{\circledR}$ (Bionix Medical Technologies, Toledo, $\mathrm{OH}, \mathrm{USA}$ ), is an instrument that provides tactile distraction during painful procedures.

Berberich and Landman ${ }^{28}$ used a tactile distraction tool similar to the ShotBlocker ${ }^{\circledR}$ to evaluate pain reduction during vaccination. Evaluation tools used in this study include the FPS-R and the FLACC (Faces, Legs, Activity, Crying, Consolability) scale. While the tactile distraction instrument significantly reduced pain and anxiety $(P<0.013)$, the researchers took a multimodal approach to vaccination pain relief and also utilized vapocoolant spray to the vaccination site and vibration to the unvaccinated arm. ${ }^{28}$ Interestingly, according to the results of the FPS-R, parent VAS scale for pain and anxiety, heart rate monitoring, CAMPIS, and OSBD measurement tools, when ShotBlocker ${ }^{\circledR}$ was used as a singular intervention, vaccination pain was not significantly reduced $(P<0.30)^{30}$ (see Table 2 ).

Recently, researchers have investigated tactile distraction facilitated by parents and $\mathrm{HCPs}^{30,31}$ (see Table 2). Parentled tactile distraction consisted of rubbing the child's leg that would receive the injection for 15 seconds prior to the procedure. Tools used in this study include VAS scoring from parents and research assistants, MBPS, and MAISD. No significant decrease in pain $(P<0.57)$ was associated with parent-led tactile distraction. ${ }^{30}$ In contrast, Kashaninia et $\mathrm{al}^{31}$ found, in results from the neonatal infant pain scale (NIPS), significantly lower pain associated with vaccination $(P<0.001)$ when a mother held her infant skin-to-skin with gentle pressure on the back before and during the injection.

\section{Blowing distraction}

Pain-related stress behaviors have led to the investigation of cognitive interventions to decrease pain and distress in children. ${ }^{32}$ The cognitive-behavioral intervention must provide greater stimulus to the child than the needle ${ }^{33}$ (see Table 2). Beran et $\mathrm{al}^{33}$ examined a highly engaging and novel distraction through the use of a humanoid robot. The robot would speak to the child and ask him or her to blow a bubble as the nurse administered the vaccination. The robot-led blowing distraction significantly reduced distress and pain during the vaccination $(P<0.01)^{33}$ according to results of VAS scoring from the child, parent, HCP, and researcher.

Bowen and Dammeyer ${ }^{34}$ (see Table 2) also implemented a blowing distraction in their study, which encouraged the child to blow on a noisemaker or pinwheel. The tool was designed specifically for this study, yet was similar to tools used in studies investigating childhood injections, and included 
input from the child, parent, and nurse. Parents reported significantly less distress and pain from their child when the noisemaker was the intervention $(P<0.01){ }^{34}$

Similarly, Boivin et a ${ }^{35}$ (see Table 2) examined the effectiveness of blowing bubbles in addition to the application of an anesthetic patch prior to the vaccination. The results were significant for reducing pain in children 4-9 years of age $(P<0.019)$ but were not significant in children older than 10 years of age $(P<0.5)$. Tools used for evaluation included, FPS-R, CHEOPS, and VAS scores by the parent and HCP. However, it is difficult to determine whether the pain relief reported in younger children was attributed to the blowing distraction, the anesthetic patch, or the combination of the two interventions.

\section{Oral distraction}

Studies have shown that oral administration of sucrose or breast milk prior to and during painful procedures elicits an opioid-receptor-dependent analgesia with rapid onset that lasts for several minutes. ${ }^{36-38}$ As a result, several studies have examined the effectiveness of sucrose and breastfeeding in reducing vaccination pain.

Four studies found significant reduction in pain response and crying time with breastfeeding or administering sucrose ${ }^{39-42}$ (see Table 2). Dilli et $\mathrm{al}^{41}$ compared breastfeeding with no intervention in infants less than 6 months old in lowering vaccination pain. The authors also examined the effectiveness of lidocaine and sucrose administration in children 6 months to 2 years of age using crying time, NIPS, and CHEOPS as measurement tools. All three interventions significantly lowered crying time and pain response $(P<0.001)$; however, there was not a significant difference between the lidocaine intervention and sucrose administration. ${ }^{41}$ Hatfield ${ }^{39}$ examined oral administration of sucrose prior to and after the injection using the University of Wisconsin Children's Hospital pain scale. The control group was given sterile water. There was a significantly lower crying time in the infants given oral sucrose before and after the injection $(P<0.0001) .{ }^{39}$

Breastfeeding was also examined by two groups of researchers as an intervention to reduce vaccination-related pain. The researchers compared breastfeeding with the child being restrained by a parent during the injection. In the breastfed group, there was a significant reduction in crying time and pain response with significance of $P<0.005$ using the NIPS and FPS pain scales ${ }^{40}$ and $P<0.001^{42}$ monitoring heart rate, oxygen saturations, and crying time; however, the positioning of the infant may have had a strong influence on the outcomes of these studies (see Table 2).

\section{Patient positioning}

Evidence suggests that a sitting position during painful procedures is accompanied by a greater sense of control. When forced to lie down during a painful procedure infants will commonly cry and struggle to sit up. ${ }^{43}$ Notwithstanding the benefit of sitting during a painful procedure, infants and children receiving vaccinations are traditionally positioned in a supine position for the injections. ${ }^{44}$

Three studies investigated the influence of positioning on vaccination pain (see Table 3 ). Kashaninia et $\mathrm{al}^{31}$ investigated a developmentally appropriate positioning known as Kangaroo-Care (KC) on vaccination related pain. $\mathrm{KC}$ requires the infant, wearing only a diaper, be placed on the bare skin of a parent. The authors reported that during and after the injection, there was a significant reduction in pain expressed as well as a decrease in crying time in the KC group $(P<0.001)$ using the NIPS scale. In fact, $36 / 50$ or $72 \%$ of the infants who had $\mathrm{KC}$ during the vaccination did not cry at all during the procedure. ${ }^{31}$

Ipp et $\mathrm{al}^{44}$ also investigated the mother holding her infant during the vaccination versus having the infant lie on the examination table during the vaccination. The participants in the study were 2-6 months old. The measuring tools included the neonatal Facial Coding System, VAS scale completed by the pediatrician, and crying time. There was not a significant difference in pain reduction in infants being held versus lying down $(P<0.26)$.

One study evaluated the effect of positioning on fear and perception of pain in children 4-6 years of age using the Child Medical Fear Scale and the Wong-Baker FACES scale. ${ }^{45}$ Children were randomized into two groups, sitting up versus lying down during their vaccination. Crying time was significantly longer for the children lying down $(P<0.097)$, and fear was significantly increased $(P<0.01)$. However, there was not a significant difference in reduction of pain in either group. ${ }^{45}$

\section{Vaccination $\mathrm{pH}$}

Another consideration in vaccine-related pain reduction is the order in which vaccinations are administered. When comparing diphtheria, tetanus, acellular pertussis, and Haemophilus influenzae type $\mathrm{b}$ (DTaP-Hib) and the pneumococcal conjugate vaccine (PCV), ${ }^{46}$ according to MBPS and VAS parent responses, infants experienced significantly less pain $(P<0.001)$ when the DTaP-Hib is administered before the $\mathrm{PCV}$ vaccination. The increased pain with $\mathrm{PCV}$ is thought to be related to the $\mathrm{pH}$ of the vaccine. When administering the more painful vaccine first, anxiety and attention to the procedure is 


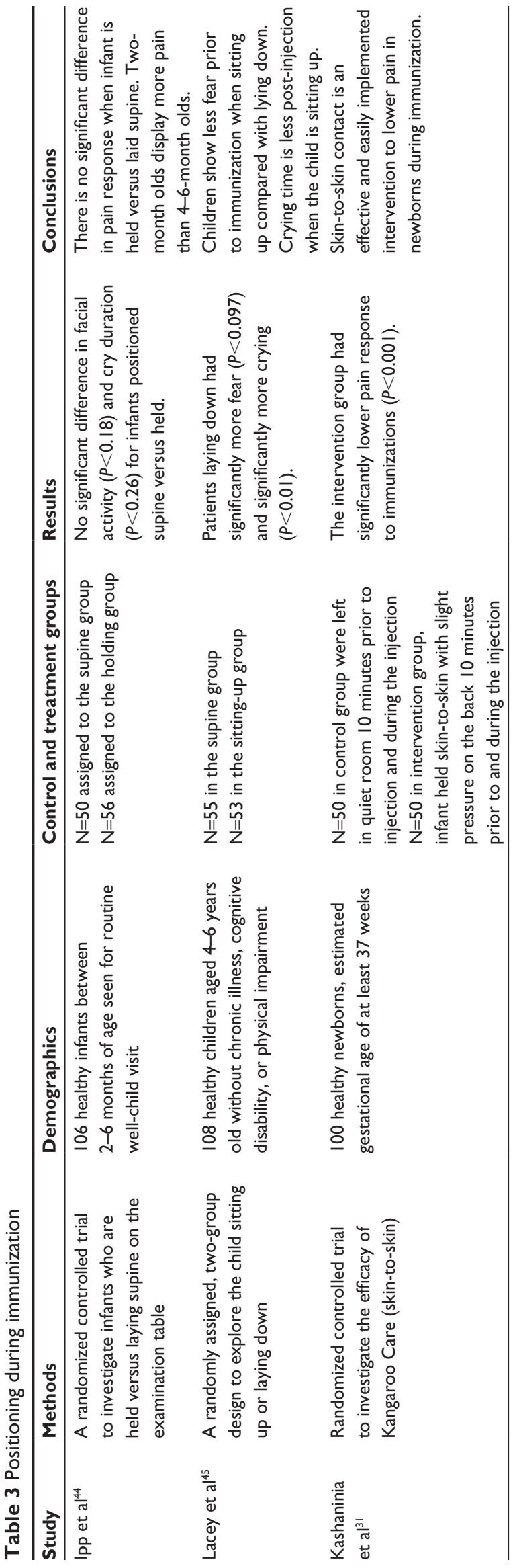

heightened. Therefore, it is beneficial to first administer the least painful vaccine, which is also the least acidic. ${ }^{46}$

Three studies investigated the vaccination Priorix as compared with the Measles, Mumps, and Rubella Vaccine (MMRII) ${ }^{47-49}$ In all three of these studies, post-injection pain was significantly reduced with the use of Priorix versus MMRII brand of measles, mumps, and rubella (MMR) vaccination $(P<0.008-0.001)$. Priorix has a $\mathrm{pH}$ of approximately 7.2, whereas MMRII has a pH of approximately 6.2. Ipp et $\mathrm{al}^{47}$ evaluated pain using the Oucher self-report scale, VAS, and crying time post-vaccination. Ipp et $a 1^{48}$ measured effectiveness using the parent VAS scores and MBPS scores, and Knutsson et $\mathrm{al}^{49}$ evaluated pain response using CHEOPS and VAS scores.

Wood et a ${ }^{50}$ compared pain levels using FPS-R when Priorix was used versus RORVax, another brand of the MMR vaccination in participants between the ages of 4 and 6 years $(n=623)$. The authors reported a significant decrease of pain immediately after injection in participants who received the Priorix vaccination $(P<0.001)$. The authors also assessed the injection site over 4 days post-vaccination and found significantly lower pain scores in the Priorix group. Similar to MMRII, RORVax has a slightly more acidic $\mathrm{pH}$ (6.66), than Priorix (see Table 4).

\section{Discussion}

Based on the available research findings, the results of this literature review found effective, ineffective, and unknown efficacy among a variety of interventions. Effective interventions may be recommended and promoted among outpatient pediatric clinics.

\section{Effective measures \\ Topical anesthetic}

Lidocaine-prilocaine cream is proven to be effective in the reduction of vaccination pain in children 4-6 years of age as well as infants 12 months of age. ${ }^{16,18,21,20}$ However, topical anesthetic is more effective when combined with distraction techniques..$^{15,19}$

\section{Distraction}

Music is a successful technique to reduce distress and pain during vaccinations in adolescents. ${ }^{26} \mathrm{~A}$ successful distraction technique for children is to blow on a party blower during vaccinations. ${ }^{34}$ Party blowers are inexpensive and easy to implement. Comparatively, the successful distraction of a robot during vaccinations is not easy to employ. ${ }^{33,34}$ Just as blowing is helpful in reducing vaccination pain in children, 


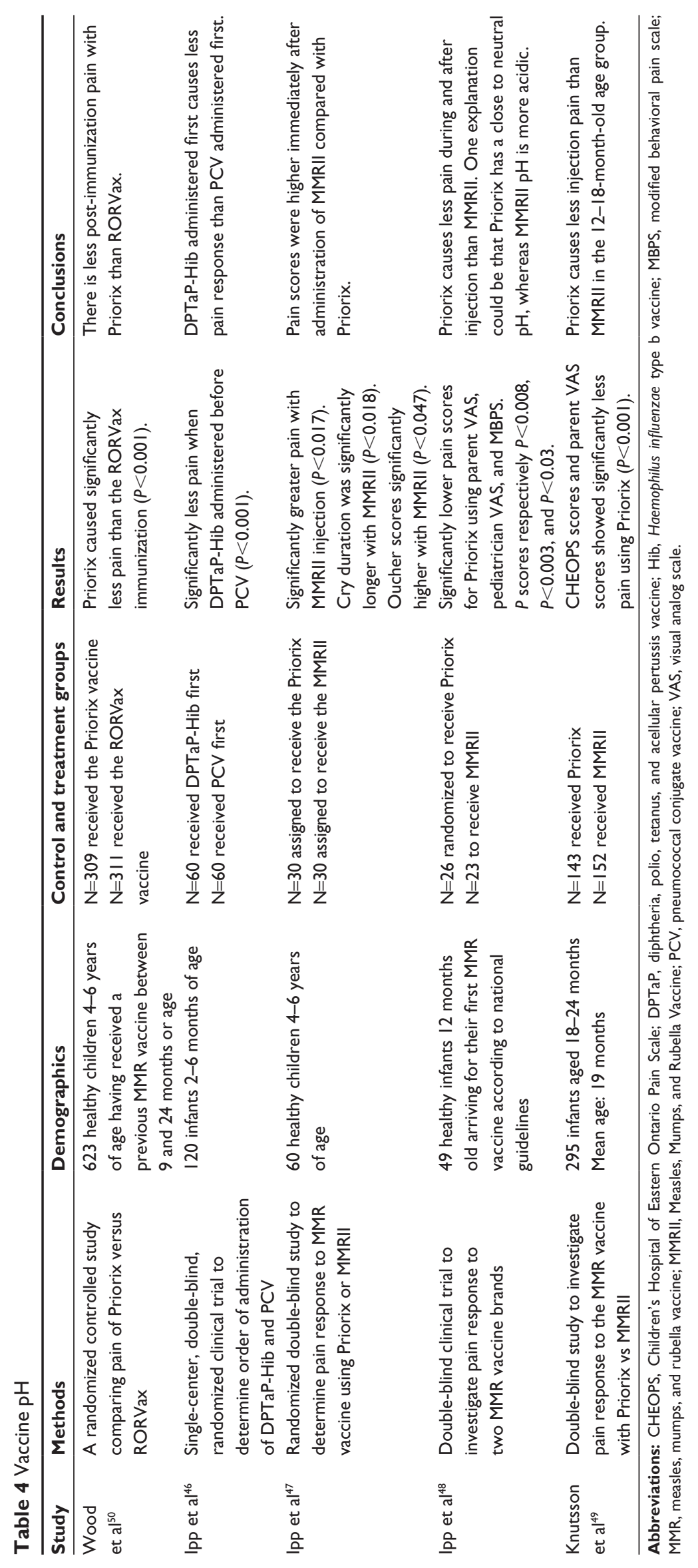


oral distraction with sucrose or breastfeeding is a successful distraction technique for infants. ${ }^{39-42}$

\section{Positioning}

Newborns should be held during vaccinations, whereas children have less distress in a sitting-up position. ${ }^{31,45}$ Additionally, $\mathrm{KC}$ is effective in reducing vaccination pain in newborns. ${ }^{31}$ Conclusively, age is an important variable when implementing pain interventions during vaccinations.

\section{Vaccine $\mathrm{pH}$}

The PCV vaccine is more acidic than DTaP-Hib, thus more painful on injection. Therefore, DTaP-Hib should be given prior to $\mathrm{PCV}^{46}$ Likewise, the brand of the vaccine can influence pain based on the $\mathrm{pH}$ of the contents. ${ }^{47-50}$ Vaccines that are less acidic are effective in lowering vaccination pain and can be easily combined with other interventions.

\section{Ineffective measures}

\section{Distraction}

Video distraction does not significantly reduce pain during the vaccination procedure. However, it does help relieve anxiety before and after vaccinations. ${ }^{23-25}$ Music is not an effective distraction technique for younger children. ${ }^{7}$

\section{Positioning}

Positioning during vaccinations does not reduce pain or crying time in infants $2-6$ months of age. ${ }^{44}$ The results in these studies provided adequate evidence to deem the interventions ineffective. Some of the research findings were not as clear on the efficacy of the intervention and require further investigation.

\section{Unknown efficacy}

\section{Tactile distraction}

The research on tactile distraction had varying results with a lack of control for variables. For example, the investigation of $\mathrm{KC}$ was compared with infants lying in a crib during vaccinations. In this study the variable of tactile distraction was not controlled, therefore effectiveness of $\mathrm{KC}$ may be inappropriately evaluated. ${ }^{31}$ Moreover, investigation of the ShotBlocker ${ }^{\circledR}$ had varying results, with few studies investigating the instrument alone without combining other distraction techniques. ${ }^{28,29}$ As a result, the level of efficacy of tactile distraction is unclear. ${ }^{28-30}$

\section{Vapocoolant}

The results from the vapocoolant studies are varied on the effectiveness in pain reduction ${ }^{15,17,19}$ and require further investigation. In the Luthy et $\mathrm{al}^{23}$ study, vapocoolant spray did not significantly reduce pain; however, the study was underpowered, there was random selection of variables, and the participants were of a wide range of ages.

\section{Implications for practice}

While a direct relationship between vaccination pain interventions and compliance with the vaccination schedule was not measured in any of the studies included in this review, other studies have evaluated the relationship between untreated pain and fear of needles with adherence to the vaccination schedule. Often, vaccine-related pain, crying, and anxiety of pediatric patients causes a high level of anxiety for the patients' parents, thus promoting the parental procrastination of future vaccinations. ${ }^{10,50,52}$ In fact, one out of every 12 patients will delay vaccinations because of needle fear. ${ }^{53}$ Consequently, vaccination-related pain is a notable barrier to timely vaccination ${ }^{10,51-55}$ and should not be ignored.

Because there can be long-term sequelae from childhood painful procedures, ${ }^{6}$ HCPs should implement measures to reduce vaccination-related pain. Some HCPs may view pain from vaccinations as benign and unavoidable, ${ }^{7}$ thus thoughts of implementing measures to reduce pain during vaccinations may be cumbersome and timeconsuming. However, the results of this literature review provide intervention recommendations based upon the significant findings of studies currently available in the literature.

\section{Newborns}

Newborns should be held in the parent's arms during vaccinations. $\mathrm{KC}$ seems to be effective in lowering distress and pain as well as administration of sucrose or breastfeeding during vaccination administrations.

\section{Infants}

Infants who are breastfed or administered sucrose during vaccinations seem to have lower distress and pain. The positioning of infants 2-6 months of age does not seem to change the pain score or decrease crying time.

\section{Young children}

Multifaceted interventions seem to be effective in young children during vaccinations. They should be placed in a sitting position and offered a party blower. If time allows, lidocaine-prilocaine cream can be applied prior to injection. 


\section{Adolescents}

Adolescents should be offered the opportunity to listen to their choice of music before, during, and after the vaccination procedure, as this seems to be effective in lowering pain and distress. Additionally, if time allows, lidocaine-prilocaine cream can be applied prior to injection.

\section{Limitations}

Research on methods of pain reduction during vaccination is lacking. While there are numerous interventions for reducing vaccination pain and various pain evaluation tools, there is a lack of continuity in the available research. Studies investigating different techniques for pain relief during vaccination use varied study designs, evaluation tools, and age ranges. Additionally, some studies incorporated several different intervention techniques, making it difficult to determine which intervention clearly reduced vaccination pain. Finally, many of the studies regarding vaccination pain have small sample sizes.

The lack of available literature makes it difficult to definitively determine which intervention techniques are most effective in reducing vaccination pain. The recommendations in this review are based on the available literature and the significant findings from the studies. More research in this limited area must be completed before definitive guidelines can be created.

\section{Implications for further research}

The research on reducing pain during invasive procedures is very broad. Most pain-relieving strategies have been studied with more invasive procedures such as venous catheterization and lumbar puncture. ${ }^{56}$ There is a need for further research on distress- and pain-reduction strategies that are age specific and vaccination related.

Many of the studies in this review included combined interventions as well as small sample sizes. When painrelieving strategies are combined, it is difficult to determine which strategy is responsible for reducing the vaccinationrelated pain. Therefore, additional research is needed to repeat some of these studies with larger sample sizes to better accommodate generalization and the effectiveness of single and combined interventions.

There is a knowledge gap between what is known about vaccination pain management and what is actually practiced in the clinical setting. ${ }^{6}$ Further research is needed to identify specific barriers and HCP hesitancy to implement pain control with vaccinations in the outpatient setting. Discovering the gaps of implementing research into practice will assist with improved recommendations and provider education.

\section{Conclusion}

Pain experienced at a young age can have psychologically detrimental effects. Vaccinations are the most common painful procedure for infants and children and often result in decreased adherence to the vaccination schedule. The HCP has a responsibility to incorporate effective painrelieving strategies with vaccinations. The information presented in this review provides HCPs with age appropriate guidance on pain-relieving interventions during vaccinations. Many of these strategies are cost-efficient, timely, and effective, making them successful pain-management techniques.

\section{Disclosure}

The authors report no conflicts of interest in this work.

\section{References}

1. Institute of Medicine [homepage on the Internet]. Childhood immunization schedule and safety: stakeholder concerns, scientific evidence, and future studies. Updated January 16, 2013. Available from: http:// www.iom.edu/Reports/2013/The-Childhood-Immunization-Scheduleand-Safety.aspx. Accessed July 14, 2014.

2. World Health Organization. World health assembly endorses new plan to increase global access to vaccines [press release]. Geneva: World Health Organization; [May 25, 2012]. Available from: http://www.who. int/immunization/newsroom/press/wha_endorses_gvap/en. Accessed July 14, 2014.

3. World Health Organization. No vaccine for the scaremongers. Bull World Health Organ. 2008;89(6):417-496.

4. US Department of Health and Human Services. Health, United States, 2012: with Special Feature on Emergency Care. Hyattsville, MD: US Department of Health and Human Services; 2013. Available from: http://www.cdc.gov/nchs/data/hus/hus12.pdf\#078. Accessed July 14, 2014.

5. Centers for Disease Control and Prevention [homepage on the Internet]. Recommended immunization schedule for persons 0 through 18 years. Atlanta, GA: Centers for Disease Control and Prevention; [updated January 31, 2014]. Available from: http://www.cdc.gov/vaccines/schedules/ hcp/imz/child-adolescent.html. Accessed July 14, 2014.

6. Taddio A, Shah V, Leung E, et al. Knowledge translation of the HELPin KIDS clinical practice guideline for managing childhood vaccination pain: usability and knowledge uptake of educational materials directed to new parents. BMC Pediatr. 2013;13(23):1-9.

7. Megel ME, Houser CW, Gleaves LS. Children's responses to immunizations: lullabies as a distraction. Compr Pediatr Nurs. 1998;21:129-145.

8. Brady K, Avner JR, Khine H. Perception and attitude of providers toward pain and anxiety associated with pediatric vaccine injection. Clin Pediatr. 2011;50(2):140-143.

9. Luthy KE, Beckstrand RL, Callister LC. Parental hesitation in immunizing children in Utah. Public Health Nurs. 2010;27(1):25-31.

10. Luthy KE, Beckstrand RL, Asay W, Hewett C. Vaccinating parents experience vaccine anxiety too. J Am Assoc Nurse Pract. 2013;25(12):667-673.

11. Wright S, Yelland M, Heathcote H, Ng S, Wright G. Fear of needles nature and prevalence in general practice. Aust Fam Physician. 2009;38(3):172-176.

12. Taddio A, Chambers CT, Halperin SA, et al. Inadequate pain management during routine childhood immunizations: the nerve of it. Clin Ther. 2009;31 Suppl 2:S152-S157. 
13. Jacobson RM, Swan A, Adegbenro A, Ludington SL, Wollen PC, Polland GA. Making vaccines more acceptable - methods to prevent and minimize pain and other common adverse events associated with vaccines. Vaccine. 2001;19(17-19):2418-2427.

14. Srouji R, Ratnapalan S, Schneeweiss S. Pain in children: assessment and nonpharmacological management. Int J Pediatr. 2010;2010:1-11.

15. Abbott K, Fowler-Kerry S. The use of a topical refrigerant anesthetic to reduce injection pain in children. J Pain Symptom Manage. 1995;10(8):584-590.

16. Cassidy KL, Reid GJ, McGrath PJ, Smith DJ, Brown, TL, Finley GA. A randomized double-blind, placebo-controlled trial of the EMLA patch for the reduction of pain associated with the intramuscular injection in four to six-year-old children. Acta Paediatr. 2001;90(11): 1329-1336.

17. Cohen LL, MacLaren JE, DeMore M, et al. A randomized controlled trial of vapocoolant for pediatric immunization distress relief. Clin J Pain. 2009;25(6):490-494.

18. Halperin BA, Mcgrath P, Smith B, Houston T. Lidocaine-prilocaine patch decreases the pain associated with the subcutaneous administration of measles-mumps-rubella vaccine but does not adversely affect the antibody response. J Pediatr. 2000;136(6):789-794.

19. Reis EC, Holubkov R. Vapocoolant is equally effective as EMLA cream in reducing immunization pain in school aged children. Pediatrics. 1997; 100:e5

20. Taddio A, Nulman I, Goldbach M, Ipp M, Koren G. Use of lidocaine-prilocaine cream for vaccination pain in infants. $J$ Pediatr. 1994;124(4):643-648.

21. Uhari M. A eutectic mixture of lidocaine and prilocaine for alleviating vaccination pain in infants. Pediatrics. 1993;92(5):719-722.

22. Powers SW. Empirically supported treatments in pediatric psychology: procedure-related pain. J Pediatr Psychol. 1999;24(2):131-145.

23. Luthy KE, Beckstrand RL, Pulsipher A. Evaluations of methods to relieve parental perceptions of vaccine-associated pain and anxiety in children: a pilot study. J Pediatr Health Care. 2013;27(5): 351-358.

24. Cohen LL, MacLaren JE, Forston BL, et al. Randomized clinical trial of distraction for infant immunization pain. Pain. 2006;125(1-2):165-171.

25. Cohen LL. Reducing infant immunization distress through distraction. Health Psychol. 2002;21(2):207-211.

26. Kristjansdottir O, Kristjansodottir G. Randomized clinical trial of musical distraction with and without headphones for adolescents' immunization pain. Scand J Caring Sci. 2011;25(1):19-26.

27. Melzack R, Wall PD. Pain mechanisms: a new theory. Science. 1965;150(3699):971-979.

28. Berberich FR, Landman Z. Reducing immunization discomfort in 4- to 6-year-old children: a randomized clinical trial. Pediatrics. 2009;124(2):e203-e209.

29. Cobb JE, Cohen LL. A randomized controlled trial of the ShotBlocker for children's immunization distress. Clin J Pain. 2009;25(9): 790-796.

30. Hogan ME, Probst J, Wong K, Riddell RP, Katz J, Taddio A. A randomizedcontrolled trial of parent-led tactile stimulation to reduce pain during infant immunization injections. Clin J Pain. 2014;30(3):259-264.

31. Kashaninia Z, Sajedi F, Rahgozar M, Noghabi FA. The effect of kangaroo care on behavioral responses to pain of an intramuscular injection in neonates. J Spec Pediatr Nurs. 2008;13(4):275-280.

32. Broome ME, Rehwaldt E, Fogg L. Relationships between cognitive behavioral techniques, temperament, observed distress, and pain reports in children and adolescents during lumbar puncture. J Pediatr Nurs. 1998;13(1):48-54.

33. Beran TN, Ramirez-Serrano A, Vanderkooi OG, Kuhn S. Reducing children's pain and distress towards flu vaccinations: a novel and effective application of humanoid robotics. Vaccine. 2013;31(25): 2772-2777.

34. Bowen AM, Dammeyer MM. Reducing children's immunization distress in a primary care setting. J PediatrNurs. 1999;14(5):296-303.
35. Boivin JM, Lemarquis LP, Iraqi W, Fay R, Schmitt C, Rossignol P. A multifactorial strategy of pain management is associated with less pain in schedule vaccination of children. A study realized by family practitioners in 239 children aged 4-12 years old. Fam Pract. 2008;25(6):423-429.

36. Anseloni CZ, Weng HR, Terayama R, et al. Age dependency of analgesia elicited by intraoral sucrose in acute and persistent pain models. Pain. 2002;97:93-103.

37. Ruda MA, Ling QD, Hohmann AG, Peng YB, Tachibana T. Altered nociceptive neuronal circuits after neonatal peripheral inflammation. Science. 2000;289(5479):628-631.

38. Ramenghi LA, Evans DJ, Levene MI. "Sucrose analgesia": absorptive mechanism or taste perception? Arch Dis Child Fetal Neonatal Ed. 1999;80(2):146-147.

39. Hatfield L. Sucrose decreases infant biobehavioral pain response to immunizations: a randomized controlled trial. J Nurs Scholarsh. 2008;40(3):219-225.

40. RazekAA, El-Dein NA. Effect of breast-feeding on pain and relief during infant immunization injections. Int J Nurs Pract. 2009;15(2):99-104.

41. Dilli D, Kucuk IG, Dallar Y. Interventions to reduce pain during vaccination in infancy. J Pediatr. 2009;154(3):385-390.

42. Efe E, Ozer AC. The use of breast-feeding for pain relief during neonatal immunization injections. Appl Nurs Res. 2007;20(1):10-16.

43. Catlin C, Tordjman S, Moren E, Oger V, Sizsun J. Clinical, physiologic, and biologic impact of environmental and behavioral interventions on neonate during a routine nursing procedure. J Pain. 2005;6(12):791-797.

44. Ipp M, Taddio A, Goldbach M, David SB, Stevens B, Koren G. Effects of age, gender and holding on pain response during infant immunization. Can J Clin Pharmacol. 2004;11(1):e2-e7.

45. Lacey CM, Finkelstein M, Thygeson MV. The impact of positioning on fear during immunizations: supine versus sitting up. J Pediatr Nurs. 2008;23(3):195-200.

46. Ipp M, Parkin P, Lear N, Goldback M, Taddio A. Order of vaccine injection and infant pain response. Arch Pediatr Adoles Med. 2009; 163(5):469-472.

47. Ipp M, Cohen E, Goldback M, Macarthur C. Pain response to M-M-R vaccination in 4-6 year old children. Can J Clin Pharmacol. 2006;13(3):e296-e299.

48. Ipp M, Cohen E, Goldback M, Macarthur C. Effect of choice of measlesmumps-rubella vaccine on immediate vaccination pain in infants. Arch Pediatr Adolesc Med. 2004;158(4):323-326.

49. Knutsson N, Jansson UB, Alm B. Immediate injection pain in infants aged 18 months during vaccination against measles, mumps, and rubella with either Priorix or MMR-II. Vaccine. 2006;24(31-32):5800-5805.

50. Wood C, Von-Baeyer CL, Bourrillon A, Dejos-Conant V, Clyti N, Abitbol V. Self-assessment of immediate post-vaccination pain after two different MMR vaccines administered as a second dose in 4- to 6-year old children. Vaccine. 2004;23(2):127-131.

51. Schechter NL, Zempsky WT, Cohen LL, McGrath PJ, McMurtry CM, Bright NS. Pain reduction during pediatric immunizations: evidence-based review and recommendations. Pediatrics. 2007;119(5):e1184-e1198.

52. Luthy KE, Beckstrand RL, Peterson NE. Parental hesitation as a factor in delayed childhood immunization. J Pediatr Health Care. 2009;23(6):388-393.

53. Taddio A, Ipp M, Thivakaran S, et al. Survey of the prevalence of immunization non-compliance due to needle fears in children and adults. Vaccine 2012;30(32):4807-4812.

54. Hogan M, Kikuta A, TaddioA. A systematic review of measures for reducing injection pain during adult immunization. Vaccine. 2010;28(6):1514-1521.

55. Gidudu JF, Walco GA, Taddio A, et al. Immunization site pain: case definition and guidelines for collection, analysis, and presentation of immunization safety data. Vaccine. 2012;30(30):4558-4577.

56. Kleiber C, Harper DC. Effects of distraction on children's pain and distress during medical procedures: a meta-analysis. Nurs Res. 1999;48(1):44-49. 
Pediatric Health, Medicine and Therapeutics

Dovepress

\section{Publish your work in this journal}

Pediatric Health, Medicine and Therapeutics is an international, peerreviewed, open access journal publishing original research, reports, editorials, reviews and commentaries. All aspects of health maintenance, preventative measures and disease treatment interventions are addressed The manuscript management system is completely online and includes a very quick and fair peer-review system. Visit http://www.dovepress.com/ testimonials.php to read real quotes from published authors.

within the journal. Practitioners from all disciplines are invited to submit

Submit your manuscript here: http://www.dovepress.com/pediatric-health-medicine-and-therapeutics-journal 